\title{
Representação política de mulheres: um estudo sobre a incorporação da agenda de gênero no âmbito legislativo do Equador (2009-2017)
}

\section{Women's political representation: a study on the incorporation of the gender agenda in Ecuador's legislative power (2009-2017)}

Recebido em: 30 de janeiro de 2018

Aprovado em: 08 de julho de 2018

DOI: 10.5752/P.2317-773X.2019v7.n1.p63

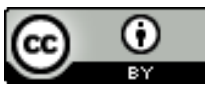

1. Doutoranda em Ciência Política (DCP) pela Universidade Federal de Minas Gerais (UFMG). Mestre em Relações Internacionais pela Pontifícia Universidade Católica de Minas Gerais (PUC Minas). Bacharela em Relações Internacionais pela Pontifícia Universidade Católica de Minas Gerais (PUC Minas). Belo Horizonte/Brasil. ORCID: 0000-00026192-7825. (ID)

Bárbara Lopes Campos ${ }^{1}$

RESUMo

Nosso trabalho consiste em um estudo de caso exploratório sobre a relação entre a representação política de mulheres e a incorporação da agenda de gênero no Equador. Temos por objetivo analisar como a representação descritiva de mulheres no poder legislativo equatoriano influencia a representação substantiva de mulheres, em termos da produção de políticas públicas voltadas para questões de gênero e de direitos das mulheres. O marco teórico do trabalho é embasado em perspectivas feministas, especialmente de autoras de Relações Internacionais. Realizamos um estudo de caso exploratório sobre a representação de mulheres na Assembleia Nacional da República do Equador, analisando: 1) os projetos de lei propostos voltados para a temática de gênero; 2) e a atuação das deputadas eleitas no contexto de pós-implementação das políticas de cotas legislativas. Entendemos que a representação descritiva de mulheres influenciou a representação substantiva de mulheres no Equador, uma vez que a presença e a atuação das deputadas, juntamente com os projetos de lei aprovados, contribuem para o processo de despatriarcalização e de transformação do sistema hegemônico masculino, no sentido da promoção da igualdade entre homens e mulheres na sociedade.

Palavras-chave: Gênero. Representação de Mulheres. Equador. Agenda de Gênero. Despatriarcalização.

\footnotetext{
ABSTRACT

Our paper consists of an exploratory case study on the relationship between women`s political representation and the incorporation of the gender agenda in Ecuador. We aim to analyze how the descriptive representation of women in the Ecuadorian legislative power influences the substantive representation of women in terms of public policies focused on gender issues and women's rights. The theoretical framework is based on feminist perspectives of International Relations. We carried out an exploratory case study on women`s representation in the National Assembly of the Republic of Ecuador analyzing: 1) proposed bills focused on gender issues; 2 ) the performance of female
} 
elected representatives in the context of the post-implementation of legislative quota policies. We understand that the descriptive representation of women has influenced the substantive representation of women in Ecuador since the presence of female deputies together with approved bills contributed to the process of depatriarchalization and transformation of the masculine hegemonic system promoting equality between men and women in society.

Keywords: Gender. Women's Representation. Ecuador. Gender Agenda. Depatriarchalization.

Introdução

Nosso trabalho se insere na temática da formação de uma agenda internacional feminista na região latino-americana, e diz respeito à participação de mulheres no processo de elaboração de políticas públicas voltadas para questões de gênero em países da América Latina. O trabalho consiste em um estudo sobre a influência da representação de mulheres, em processos decisórios da política nacional, na incorporação da agenda de gênero no Equador. Especificamente, queremos descobrir como a representação descritiva de mulheres influencia a representação substantiva de mulheres, no sentido de promover políticas públicas voltadas para questões de gênero e direitos das mulheres no país.

Para tal, realizamos um estudo de caso exploratório sobre a representação de mulheres na Assembleia Nacional da República do Equador, com a intenção de entender a incorporação de questões de gênero na política equatoriana, através dos projetos de lei propostos e da atuação das deputadas eleitas, no contexto de pós-implementação de políticas de cotas legislativas - pós 2009. O caso equatoriano aparece como chave para o contexto aqui proposto, uma vez que o país possui algumas características consideradas importantes para a realização da análise sobre a representação descritiva e substantiva de mulheres. Em primeiro lugar, o país passou por uma reformulação política em 2006, se inserindo no contexto da onda rosa na América Latina e elaborando uma nova Constituição que aponta para um caminho progressista em termos de políticas inclusivas. Em segundo lugar, a política de cotas para mulheres implementada, apesar de recente, atingiu resultados impressionantes, possibilitando que o Equador alcançasse mais de $40 \%$ de representação feminina no parlamento nacional em apenas 5 anos.

A partir de abordagens feministas em Relações Internacionais (RI), se reconhece a importância de dar voz a iniciativas e projetos que tentam transformar a situação de desigualdade entre homens e mulheres. No âmbito da América Latina, os problemas relacionados à igualdade de gênero são pautas que tem se tornado cada vez mais presentes nos debates políticos a nível nacional e internacional, sendo que muitos dos países latino-americanos ocupam elevadas posições no ranking mundial de representatividade de mulheres na esfera política, tanto em relação à representação legislativa quanto aos mecanismos institucionais de mulheres a nível do poder executivo.

Acredita-se que os casos de sucesso de políticas de cotas para mulheres em cargos legislativos dos países da América Latina representam 
uma condição essencial para o surgimento progressivo de projetos de lei voltados para a promoção efetiva da igualdade de gênero. Tal interesse parte do intuito de compreender até que ponto a abordagem feminista que defende a inserção de mulheres na esfera política, como forma de promover uma maior justiça de gênero na sociedade, se concretiza no caso estudado. Assim, a indagação proposta remete às iniciativas de despatriarcalização do Estado, por meio da inserção de mulheres no processo de decisão política e da incorporação da agenda de gênero.

O referente estudo tem como objetivo não apenas oferecer o resultado desta pesquisa, mas, também, abrir espaço para outras indagações. A proposta contribui para as Relações Internacionais ao estudar o fenômeno da quarta onda dos movimentos feministas na América Latina e a maior representação de mulheres no Estado como formas de compreender os impactos nas desigualdades políticas e sociais entre homens e mulheres a nível sistêmico.

Entendemos que a representação descritiva de mulheres influenciou a representação substantiva de mulheres no Equador. Assim, constatamos que a composição paritária de mulheres na Assembleia Nacional, a incorporação das questões de gênero na política equatoriana por meio dos projetos aprovados, e a atuação específica das deputadas equatorianas contribuem para a ressignificação dos espaços público e privado e para o processo de despatriarcalização e de transformação do sistema hegemônico masculino, no sentido da promoção da igualdade de gênero. Além disso, apontamos para alguns limites observados ao final do trabalho.

\section{Perspectivas feministas em Rl: compreendendo o sistema} patriarcal hegemônico

A hegemonia masculina pode ser definida através do conceito de patriarcado, ou de um sistema patriarcal, que tem como base o androcentrismo e a heteronormatividade. Sylvia Walby (1991) identifica o patriarcado nas formas privada e pública, sendo que a primeira se refere à esfera doméstica - espaço excludente onde o modo de expropriação da produção é doméstica e individual; e a segunda que se refere à esfera do Estado e do mercado de trabalho - espaço segregado onde o modo de expropriação é coletivo. A ideologia de tal hegemonia de gênero, que tem um caráter intrinsecamente político, ordena modos de pensar sobre relações sociais e opera para legitimar relações específicas de poder (PETERSON; RUNYAM, 2014).

O sistema patriarcal de crenças e suas instituições, portanto, ordenam a sociedade ao estabelecerem o homem como sendo a autoridade em todas as esferas da vida social, seja como chefe de família, sacerdote religioso, exercendo funções militares ou sendo o ser que ocupa o espaço político. Nesse contexto estrutural temos, portanto, uma divisão dicotômica e sexual do trabalho na qual os homens são responsáveis pelo trabalho produtivo e as mulheres pelo trabalho reprodutivo (PETERSON; RUNYAM, 2014). Gayle Rubin (1975) demonstra, através de uma abordagem marxista, como a heterossexualidade obrigatória está diretamente relacionada com a divisão sexual do trabalho, que estabelece papeis e 
2. Do inglês: "ruling gender" (HARTSOCK, 1985, p. 9). funções diferenciadas para homens e mulheres na sociedade, de modo que está associada com a opressão sofrida pelas mulheres. E, de modo semelhante, Nancy Hartsock (1985) enfatiza a importância de se pensar na divisão sexual do trabalho, que aparece como naturalizada na sociedade, enquanto forma de controle de um determinado "gênero que governa"2.

Entendemos, portanto, que a hegemonia masculina se perpetua no ambiente internacional e se concretiza na existência de um sistema patriarcal - sustentado pelas próprias estruturas e práticas do Estado, pelas instituições da sociedade civil e pela ideologia do ideal de masculinidade -, que dá legitimidade para a segregação e divisão entre os espaços público e privado. Assim, entende-se que a modernidade marcou a emergência, não só do capitalismo, mas da dinâmica social das relações de gênero dicotômicas e antagônicas, baseadas em dominação/subjugação do patriarcado (SCHOLZ, 2014). Essa estrutura falologocêntrica, marcada por padrões de dominação, provocou a criação de demandas por desconstruções, principalmente pelo fato das mulheres serem as maiores vítimas da exacerbação da divisão internacional do trabalho, uma vez que representam o verdadeiro exército de reserva na conjuntura atual (SPIVAK, 2014).

Considerando que o trabalho em questão se dedica a políticas públicas elaboradas dentro de países latino-americanos, se torna relevante utilizar o conceito de despatriarcalização do Estado, que diz respeito às iniciativas de desconstrução das estruturas estabelecidas por realidades e conjunturas patriarcais no âmbito da política. Ou seja, trata-se "[...] dos esforços em curso de descolonização/ despatriarcalização do Estado, tomando como eixo central de análise a opressão de gênero ou de origem patriarcal, na chave de um processo de democratização social e do próprio Estado." (MATOS; PARADIS, 2014, p. 59). Nesse sentido, entende-se que o Estado patriarcal possui uma postura não democrática em termos de discriminação e manipulação de gênero, sendo necessária a sua desconstrução. No contexto latino-americano, "[...] os movimentos feministas e de mulheres, especialmente a partir dos anos 90, foram também travando a batalha da reconstrução de uma renovada consciência feminista no país [Brasil] (e na região), e com ela foram ganhando um novo contorno político." (MATOS; PARADIS, 2014, p. 94).

No sentido ainda político da importância de tais movimentos, Wendy Brown (1988) afirma que o feminismo contemporâneo aparece como uma abordagem que se direciona da margem para o centro, no sentido de criticar construções sociais masculinas em diferentes questões, discursos e instituições, para que seja possível, primeiro, interpretar e, posteriormente, transformar o mundo. Para Hannah Arendt (1994), os conceitos de política e de poder remetem à capacidade humana de agir em comum acordo, ou seja, a política corresponde à habilidade de agir em concerto, se afastando de uma noção de política ligada ao exercício da dominação. Esse entendimento da esfera política é essencial para compreendermos nosso objeto de estudo, uma vez que a noção da possibilidade de atuação do Estado no intuito de agir em concerto, desligada da ideia de dominação e uso de violência, nos ajuda e entender uma série de conquistas no sentido de defender os direitos das mulheres e a equidade de gênero por parte do Estado. 
Incorporar questões de gênero às problemáticas e abordagens de Relações Internacionais, significa assumir que a manutenção da estrutura dominante de gênero produz e reproduz dicotomias, hierarquizações, desigualdades e injustiças, que possuem consequências de proporções globais. Partindo desse pressuposto, as lentes feministas se tornam essenciais para revelar e compreender como essas estruturas de dominação sustentam desigualdades no âmbito global (PETERSON; RUNYAM, 2014). Resgatando as ideias de Cynthia Enloe (2004, p.29), que argumenta que o sistema político internacional é "habitado" por homens, podemos nos orientar pela seguinte pergunta de partida: onde estão as mulheres? E não apenas em RI no geral, mas também no mundo que RI se propõe a estudar.

Aqui, estudamos a relação entre a presença política de mulheres e a incorporação da agenda de gênero no Equador. Podemos entender agenda de gênero como:

\section{[...] a agenda-síntese dos temas priorizados por diversos atores (e atrizes), tendo como eixo as relações de gênero, não se confundindo com a agenda de nenhum grupo particular. Reúne, assim, temas e propostas levantados por mulheres participantes de movimentos populares e temas e propostas formulados pelo feminismo, em suas diferentes vertentes ${ }^{3}$ (FARAH, 2004, p. 53).}

Consideramos, ainda, que a representação descritiva de mulheres - no sentido da representação formal através de mecanismos eleitorais e designação de mulheres para cargos públicos no governo -, está muitas vezes relacionada à representação substantiva, através da incorporação das demandas dos movimentos de mulheres no processo político (LOVENDUSKI, 2005).

A quarta onda dos movimentos feministas na América Latina: 0 contexto político do Equador

A chamada quarta onda dos movimentos feministas, no contexto latino-americano, tem relação com uma nova abordagem feminista que destaca, entre outras questões, o foco no mainstreaming feminista, isto é, a verticalização em relação ao Estado e suas instituições, ao mesmo tempo em que se enfatizam ações transversais, interseccionais e intersetoriais de despatriarcalização das instituições - onde se inclui instituições estatais, sindicatos, partidos, parlamentos, empresas, entre outras (MATOS; PARADIS, 2014, p. 96). No contexto dessa quarta onda de abordagem e movimentos feministas, as mulheres se voltaram para dentro do Estado e começam a ocupar, cada vez mais, esse espaço político, sendo essenciais no processo de criação de organismos, mecanismos e estruturas que possibilitam ações despatriarcalizantes (MATOS; PARADIS, 2014).

Assim, se na esfera do poder legislativo podemos enfatizar a maior representação de mulheres a partir da emergência de políticas de cotas na região latino-americana (DAHLERUP, 2005); na esfera do poder executivo podemos enfatizar os mecanismos institucionais de mulheres, através dos quais as mulheres encontraram novas formas de representação e participação política (MATOS; PARADIS, 2014). Vale ressaltar o que ficou conhecido como a "onda rosa" na América Latina, ou seja, o fato de que: "[a] política latino-americana foi marcada na última década pela ascensão de
3. A agenda de gênero é um dos conjuntos de temas que podem compor o que John Kingdon chama de agenda sistêmica ou agenda pública (KINGDON, 1995 apud FARAH, 2004, p. 53). 
4. According to Articles 99 (1) and 160 of the 2009 Electoral Law, in the candidate lists, for the elections through the system of proportional representation, the names of men and women candidates shall alternate. In addition, Article 160 requires that candidate lists for elections to the National Assembly, the Andean and Latin American Parliament, the regional councils, as well as the district, municipal and rural councils, shall be formed with an equal number sequence (woman-man or man-woman) to complete the total number of principal and alternative candidates.

5. Article 105 (2) of the electoral law states that the candidate lists will be rejected by the Electoral Commission if they do not comply with the gender parity and alternation provisions of the

Constitution and the electoral law. partidos, movimentos e lideranças de esquerda a governos nacionais. Tal ascensão, por sua relativa sincronia e delimitação regional, constitui em si mesma um processo sócio-político único [...]” (SILVA, 2010, p.1). Dessa forma, no cenário da quarta onda feminista e da onda rosa latino-americana, diversos mecanismos apareceram como formas de institucionalizar, no interior da própria estrutura do Estado, perspectivas de mulheres (MATOS; PARADIS, 2014).

Especificamente sobre o processo político ao qual o Equador experimentou, a Revolución Ciudadana ecuatoriana impulsionou a elaboração de uma nova Constituição, na qual a esquerda, o progressismo e movimentos campesinos e indígenas - inclusive de mulheres - pudessem participar do momento de repensar o modelo neoliberal seguido até então. Apesar dos questionamentos que encaram o Alianza País de Rafael Correa como um afastamento dos interesses dos setores tradicionais das populações - principalmente após a promoção de modelos econômicos extrativistas que impactaram negativamente os direitos indígenas aos quais os governos estavam inicialmente alinhados (SCHAVELZON, 2015) -, uma visão mais inclusiva definida pela noção de Estado plurinacional pautou a nova direção da Constituição da República Del Ecuador.

No caso da inserção de mulheres na política equatoriana, teremos como ponto de partida as políticas de cotas para mulheres no legislativo nacional. O Equador aparece na nona posição do ranking mundial de 2016 (INTERPARLAMENTARY UNION, 2016), com uma porcentagem de $41,6 \%$ de mulheres ocupando cadeiras na Assembleia Nacional. O país possui cotas legislativas que estão efetivadas nos textos da Constituição e de leis eleitorais. De acordo com o Artigo 65 da Constituição de 2008, o sistema de cotas equatoriano estabelece princípios de paridade para todos os níveis eleitorais. Assim, afirma-se que o Estado deve adotar medidas de ação afirmativa para garantir a participação de parcelas discriminadas da população. Dessa forma, a legislação eleitoral estabelece que:

De acordo com os artigos 99 (1) e 160 da Lei Eleitoral de 2009, nas listas de
candidatos, para as eleições através do sistema de representação proporcional, os
nomes dos homens e mulheres candidatas serão alternados. Além disso, o artigo
160 exige que as listas de candidatos para as eleições para a Assembleia Nacional, o
Parlamento Andino, o Parlamento Latino-Americano, os conselhos regionais, dis-
trital, conselhos municipais e rurais, serão formados com uma sequência de igual
número (mulher-homem ou homem-mulher) para completar o número total de
candidatos principais alternativos (QUOTA PROJECT, 2016, s/p, tradução nossa ${ }^{4}$ ).

Além disso, o "artigo 105 (2) da lei eleitoral estabelece que as listas de candidatos serão rejeitadas pela Comissão Eleitoral caso não cumpram as disposições da Constituição e da lei eleitoral relativas à igualdade de gênero e à alternância" (QUOTA PROJECT, 2016, s/p, tradução nossa ${ }^{5}$ ). Percebemos, portanto, que o sistema de cotas equatoriano é bastante extenso e busca abarcar grande parte do aparato político do país. Em relação ao impacto na representatividade legislativa a nível nacional, constatamos que após a implementação da legislação específica sobre paridade e alternância, a representação de mulheres na Assembleia Nacional passou de $25 \%$ em 2008 - quando ocupava a $37^{\mathrm{a}}$ posição no ranking mundial para 32,3\% em 2009, 38,7\% em 2013 e 41,6\% em 2014 - representação que se mantém até o ano de 2016 (INTERPARLAMENTARY UNION, 2008; 
2009; 2013; 2014; 2016). Assim, a implementação do sistema no Equador possibilitou que a representação de mulheres em seu parlamento superasse os $40 \%$ em menos de 5 anos.

É importante mencionar que o fato dessa composição legislativa do país se concretizar, ou seja, de existir uma paridade de gênero no poder legislativo equatoriano, representa uma transformação automática na conformação do espaço político. O simples fato de depararmos com imagens de mulheres no site da Assembleia Nacional equatoriana já aponta para a existência uma outra dinâmica. A presidência da Assembleia Nacional da República do Equador do período entre 2013 e 2017 foi ocupada por três mulheres: a presidenta Gabriela Alejandra Rivadeneira Burbano, a primeira vice-presidenta Rosana Alvarado Carrión, e a segunda vice-presidenta Marcela Paola Aguiñaga Vallejo. A disposição entre homens e mulheres na Assembleia é algo destacado na página online da composição dos asambleistas, de acordo com a Figura 1. E a proporção oficial informada pela Assembleia era de 78 homens e 59 mulheres - 56,93\% e 43,07\%, respectivamente (REPÚBLICA DEL ECUADOR, 2016).

Figura 1 - Composição da Assembleia Nacional do Equador

\section{PLENO - ASAMBLEÍSTAS}

\section{LISTADO GENERAL DE ASAMBLEÍSTAS 2013-2017}

El Pleno es el máximo órgano de decisión de la Asamblea Nacional. Está integrado por la totalidad de las y los asambleístas. Para la instalación y funcionamiento del Pleno se requerirá la presencia de la mayoría absoluta de las y los miembros de la Asamblea Nacional.

Asambleistas mujeres $=59(43,07 \%)$;

Asambleistas hombres $=78(56,93 \%)$

Listado General de Asambleistas

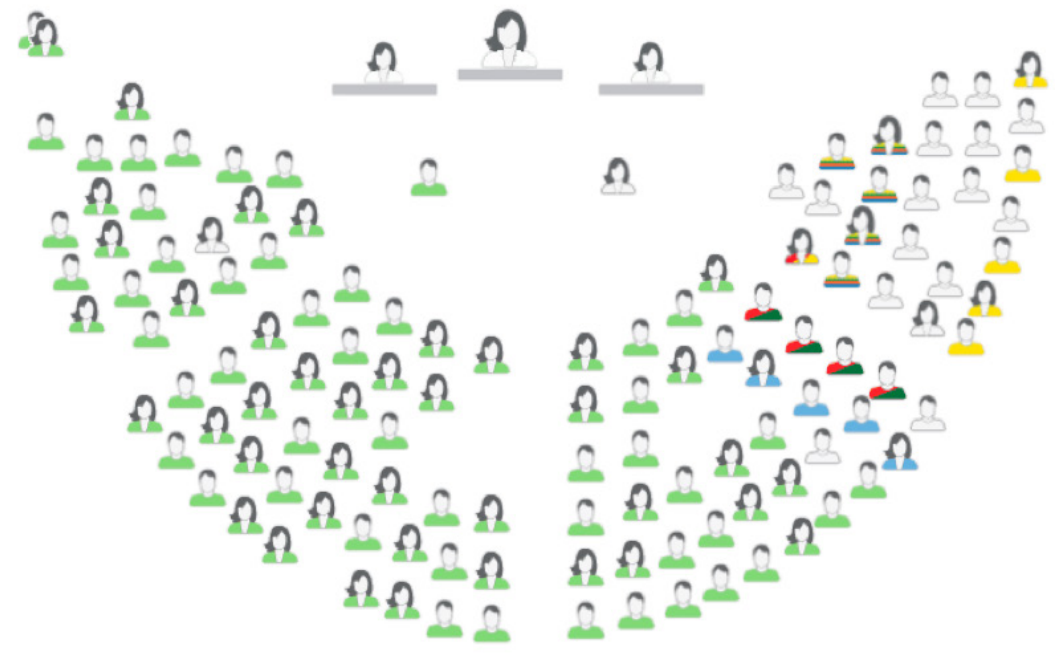

Fonte: (REPÚBLICA DEL ECUADOR, 2016).

Projetos de lei e agenda de gênero no Equador

Em nossa investigação acerca da incorporação de questões de gênero no interior do Estado equatoriano, buscando entender a influência de políticas de cotas na representação substantiva de mulheres, realizamos um estudo de caso exploratório sobre os projetos de lei voltados para a questão de gênero elaborados no Equador entre 2009 e 2017. O Quadro 1 apresenta os projetos de lei encontrados, e que serão em seguida analisados, a partir da base de dados disponibilizada pelo próprio governo equatoriano ${ }^{6}$.
6. As informações sobre os referidos projetos de lei e resolução foram retiradas do próprio banco de dados disponibilidade no site da Assembleia Nacional do Equador (ASAMBLEA NACIONAL REPUBLICA DEL ECUADOR, 2018). 
Quadro 1- Disposição dos Projetos de Lei Estudados

\begin{tabular}{l|l|l|l|l}
\hline & Projetos Aprovados & Projetos Arquivados & Projetos Unificados & Projetos em Trâmite \\
\hline $\begin{array}{l}\text { Projetos Voltados para } \\
\text { Questões de Gênero }\end{array}$ & $\begin{array}{l}1 \text { (resolução) } \\
1 \text { (projeto) }\end{array}$ & 2 & 3 & 6 \\
\hline $\begin{array}{l}\text { Projetos que Tocam } \\
\text { Questões de Gênero }\end{array}$ & 6 & $\begin{array}{l}\text { Não incluídos na } \\
\text { pesquisa }\end{array}$ & $\begin{array}{l}\text { Não incluídos na } \\
\text { pesquisa }\end{array}$ & $\begin{array}{l}\text { Não incluídos na } \\
\text { pesquisa }\end{array}$ \\
\hline
\end{tabular}

Fonte: Elaboração própria a partir do banco de dados disponível (ASAMBLEA NACIONAL REPUBLICA DEL ECUADOR, 2018).

Análise dos projetos de lei identificados

\section{Medidas vinculantes nos projetos de lei aprovados}

No primeiro momento, realizamos uma breve indicação dos projetos aprovados que possuem - ou não - medidas vinculantes em seus documentos. Estamos chamando de medidas com efeito vinculantes aquelas que estabelecem obrigatoriedade conferida a determinado enunciado com caráter jurisprudencial, de modo que seu conteúdo deve ser adotado e não apenas encarado como mera orientação (PINHEIRO, 2017). O Quadro 2 indica a relação dos projetos de lei e suas respectivas medidas vinculantes.

Quadro 2- Medidas Vinculantes dos Projetos dos Lei Aprovados

\begin{tabular}{|c|c|c|}
\hline Projetos Aprovados & Possui Medidas Vinculantes & $\begin{array}{l}\text { Não Possui Medidas } \\
\text { Vinculantes }\end{array}$ \\
\hline $\begin{array}{l}\text { Resolução para eliminar toda } \\
\text { forma de violência contra mu- } \\
\text { lheres, meninas e adolescentes }\end{array}$ & & $X$ \\
\hline $\begin{array}{l}\text { Lei Orgânica dos Conselhos } \\
\text { Nacionais para a Igualdade }\end{array}$ & $\begin{array}{l}\text { Criação do Conselho Nacional para a Igualdade de Gênero: } \\
\text { monitoramento das atividades de várias instâncias públicas; } \\
\text { obrigatoriedade de paridade na composição do conselho. }\end{array}$ & \\
\hline $\begin{array}{l}\text { Código Orgânico de } \\
\text { Organização Territorial, } \\
\text { Autonomia e Descentralização }\end{array}$ & $\begin{array}{l}\text { Criação das Comissões Permanentes de Igualdade e Gênero e dos } \\
\text { Conselhos Cantonais para a Proteção dos Direitos ligados ao órgão } \\
\text { legislativo: monitoramento das atividades das instâncias dos GADs. }\end{array}$ & \\
\hline $\begin{array}{l}\text { Lei do Esporte, Educação } \\
\text { Física e Recreação }\end{array}$ & $\begin{array}{l}\text { Obrigatoriedade da existência de equipes femininas em organiza- } \\
\text { ções esportivas; obrigatoriedade de representação paritária entre } \\
\text { homens e mulheres na composição de organizações esportivas. }\end{array}$ & \\
\hline $\begin{array}{l}\text { Lei Orgânica de Educação } \\
\text { Intercultural }\end{array}$ & & $X$ \\
\hline Lei Orgânica de Comunicação & $\begin{array}{l}\text { Obrigatoriedade de prestação de desculpas públicas por } \\
\text { parte da direção do meio de comunicação responsável a atos } \\
\text { discriminatórios; multas de até } 10 \% \text { da renda mensal do meio de } \\
\text { comunicação em casos de reincidência. }\end{array}$ & \\
\hline $\begin{array}{l}\text { Lei Reformatória à Lei de } \\
\text { Seguridade Social }\end{array}$ & $\begin{array}{l}\text { Obrigatoriedade de um salário mínimo unificado para pessoas } \\
\text { que trabalham nos setores doméstico, artesanal ou industrial. }\end{array}$ & \\
\hline $\begin{array}{l}\text { Código Orgânico Integral } \\
\text { Penal }\end{array}$ & $\begin{array}{l}\text { Diversas penas especificadas, incluindo a privação da liberdade, } \\
\text { em casos de crimes de feminicídio, abandono, violência contra a } \\
\text { mulher e à família nuclear, discriminação, e crimes de ódio. }\end{array}$ & \\
\hline
\end{tabular}


Assim, podemos observar que dentre os projetos de lei estudados que foram aprovados, apenas um não possui medidas de efeito vinculante. A Lei Orgânica de Educação Intercultural aparece como uma recomendação inclusiva sobre o direito dos cidadãos equatorianos ao acesso à educação, mas não apresenta metas específicas, mecanismos de implementação ou sanções em casos de não cumprimento (REPÚBLICA DEL ECUADOR, 2011). Além disso, a Resolução para eliminar toda forma de violência contra mulheres, meninas e adolescentes, criada na comemoração do Dia Internacional da Eliminação da Violência Contra a Mulher, também contém recomendações gerais sobre a importância de combater tais formas de violência no cenário nacional e regional (REPÚBLICA DEL ECUADOR, 2014b).

\section{Temáticas dos projetos de lei}

Em relação às temáticas abordadas nos documentos aqui estudados, identificamos que muitos deles possuem temáticas em comum e que, em muitos dos casos, múltiplas temáticas estão contidas em um mesmo projeto. Contudo, no intuito de demonstrar de forma objetiva e comparada o escopo ou eixo principal de cada projeto apresentado, organizamos em temáticas específicas de acordo com o Quadro 3.

Quadro 3- A Distribuição dos Projetos Estudados em Relação a suas Temáticas

\begin{tabular}{l|l|c|l|l|l}
\hline & $\begin{array}{l}\text { Temática 1 } \\
\text { Promoção do combate } \\
\text { à discriminação e vio- } \\
\text { lência contra mulheres }\end{array}$ & $\begin{array}{l}\text { Temática 2 } \\
\text { Promoção e trans- } \\
\text { versalização da } \\
\text { igualdade de gênero }\end{array}$ & $\begin{array}{l}\text { Temática 3 } \\
\text { Direitos das mu- } \\
\text { lheres à saúde } \\
\text { e/ou ao esporte }\end{array}$ & $\begin{array}{l}\text { Temática 4 } \\
\text { Direitos das mulheres } \\
\text { ao trabalho, seguridade } \\
\text { e/ou assistência social }\end{array}$ & $\begin{array}{l}\text { Temática 5 } \\
\text { Direitos das } \\
\text { mulheres à } \\
\text { educação }\end{array}$ \\
\hline Aprovados & 3 & 2 & 1 & 1 & 1 \\
\hline Arquivados & 2 & 0 & 0 & 0 & 0 \\
\hline Unificados & 0 & 2 & 0 & 1 & 0 \\
\hline Em Trâmite & 2 & 1 & 2 & 1 & 0 \\
\hline
\end{tabular}

Fonte: Elaboração própria a partir do banco de dados disponível (ASAMBLEA NACIO-

NAL REPUBLICA DEL ECUADOR, 2018).

Percebemos, portanto, a partir da comparação temática entre os projetos estudados no presente trabalho, que a temática da promoção do combate à discriminação e violência contra mulheres aparece com destaque, uma vez que o Código Orgânico Integral Penal, a Lei Orgânica de Comunicação e, mais recentemente, a Resolução para eliminar toda forma de violência contra mulheres, meninas e adolescentes, resultam em um aparato político e legal que possui uma série de medidas para a promoção do combate, da punição, da prevenção e da sensibilização em relação a atos de violência, perseguição ou discriminação cometidos contra mulheres no Equador (REPÚBLICA DEL ECUADOR, 2014b; REPÚBLICA DEL ECUADOR, 2014a; REPÚBLICA DEL ECUADOR, 2013). Além dos projetos de lei aprovados e que possuem medidas e metas vinculantes em relação ao cenário nacional e ao âmbito dos governos autônomos descentralizados (GADs), encontramos projetos arquivados e novos projetos em trâmite na Assembleia que abordam, também, a temática de maneira 
aprofundada, buscando garantir de forma ainda mais enfática o combate a atos de violência e discriminação, em especial à mulher - mas também a outros grupos considerados vulneráveis como crianças, adolescentes e membros da população LGBTI (GALLEGOS, 2016; GUALA, 2011; MONTEDEOCA, 2016a; MONTEDEOCA, 2012b).

De forma semelhante, percebemos que a temática da promoção e transversalização da igualdade de gênero nas instituições e na sociedade equatoriana também possui destaque nos projetos de lei estudados, uma vez que dois projetos de alcance e dimensões grandiosos foram aprovados, de modo que a Lei Orgânica dos Conselhos Nacionais para a Igualdade e o Código Orgânico de Organização Territorial, Autonomia e Descentralização caracterizam o marco de uma iniciativa política e legal para a promoção da igualdade entre homens e mulheres, em vários âmbitos da existência econômica, social, política e cultural. Nesse sentido, a institucionalização da transversalização de políticas voltadas para mulheres e para a igualdade de gênero, a nível nacional, dos GADs e municipal, proporcionam a penetração de tais pautas e agendas políticas; garantindo a elaboração, acompanhamento e monitoramento de políticas de tais natureza por meio do Conselho Nacional para a Igualdade de Gênero, das Comissões Permanentes de Igualdade e Gênero, e dos Conselhos Cantonais para a Proteção dos Direitos. Além desse enorme aparato institucional, encontramos dois projetos que foram unificados e, portanto, incorporados - mesmo que não integralmente -, são estes o Projeto de Lei de Igualdade entre Mulheres e Homens e Pessoas de Diversa Condição Sexo-genérica e o Projeto de Lei Orgânica de Igualdade entre Mulheres e Homens, garantindo que as pautas sobre a promoção integral da igualdade de gênero fossem inseridas na discussão a respeito dos Conselhos Nacionais para a Igualdade. Por fim, o Projeto de Lei Orgânica para a Participação Equitativa de Mulheres e Homens em Posições de Liderança no Setor Público e Privado, que se encontra em trâmite na Assembleia, demarca a existência de demandas para aprofundar os mecanismos institucionais de garantia à participação igualitária entre homens e mulheres em processos decisórios (REPÚBLICA DEL ECUADOR, 2010a; REPÚBLICA DEL ECUADOR, 2014c; CARANQUI, 2012; MONTEDEOCA, 2012a; MONTEDEOCA, 2016b).

Sobre a temática a respeito dos direitos das mulheres à saúde e/ ou ao esporte, apesar de termos encontrado apenas um projeto voltado para o esporte, e que aparece como importante dentro da discussão, uma vez que aborda de maneira robusta a questão da promoção igualitária de homens e mulheres em termos de oportunidades para praticar esportes e participar de processos decisórios de organizações esportivas - tendo inclusive mecanismos coercitivos e vinculantes para tal -, nos deparamos, também, com projetos novos direcionados para questões de saúde. O projeto de Lei da Prática Intercultural para o Parto Acompanhado no Sistema Nacional de Saúde e o Projeto de Lei para Prevenção, Diagnóstico, Controle e Vigilância do Câncer de Mama, aparecem, assim, como importantes iniciativas para garantir acesso amplo, inclusivo e diversificado de mulheres ao direito à saúde (REPÚBLICA DEL ECUADOR, 2010b; ANDRADE, 2012; GUALA, 2016). 
De forma semelhante, a temática dos direitos das mulheres ao trabalho, seguridade e assistência social não aparece em um volume grande de projetos aprovados, sendo alvo apenas da Lei Reformatória à Lei de Seguridade Social, que nos revela um elemento essencial para a discussão da igualdade entre homens e mulheres no âmbito do trabalho, que é a valorização do trabalho doméstico, a partir do estabelecimento de uma remuneração mínima garantida pelo Estado. Além disso, temos o Projeto de Lei que Garante a Seguridade Social a Mulheres que Realizam Trabalho Doméstico não Remunerado, projeto unificado que garante este direito adquirido; assim como o Projeto de Lei de Proteção e Assistência a Mães Adolescentes, que está em trâmite e que propõe programas de assistência a mães adolescentes e a seus filhos, em conjunto com estratégias de conscientização sobre as consequências da gravidez na adolescência, possuindo caráter, também, educativo (REPÚBLICA DEL ECUADOR, 2010c; ANDRADE, 2010; VILLARREAL, 2012).

Por fim, a temática dos direitos das mulheres à educação aparece apenas em um projeto, este aprovado, a Lei Orgânica de Educação Intercultural, que garante o acesso à educação a todas as mulheres equatorianas, apesar da ausência de mecanismos vinculantes. Porém, é importante ressaltar que a maioria dos projetos estudados - e isso se deve principalmente ao princípio constitucional da promoção integral, inclusiva e transversal da igualdade de gênero - possuem medidas educativas e de sensibilização para promover a igualdade e combater determinadas práticas; assim, desde projetos voltados para a questão da violência e discriminação contra mulheres até os projetos de inclusão da prática do parto humanizado em unidades de saúde equatorianas, por exemplo, possuem disposições educativas em suas recomendações (REPÚBLICA DEL ECUADOR, 2011).

A partir da comparação entre as temáticas dos projetos de leis estudados, podemos observar que muito se tem alcançado em relação à agenda vinculada à promoção do combate à discriminação e violência contra mulheres e à promoção e transversalização da igualdade de gênero no Equador. Tais temáticas foram atendidas com leis robustas, inclusivas, que possuem mecanismos vinculantes e que atingem diferentes níveis institucionais.

\section{Proposições dos projetos de lei}

Apresentaremos aqui, a partir do Quadro 4, a relação entre os projetos de lei estudados e a autoria dos mesmos. Assim, poderemos comparar o número de projetos voltados para questões de gênero e de mulheres que foram propostos por deputadas (mulheres), por deputados (homens), ou pelo poder Executivo (através do Presidente Constitucional da República Rafael Correa Delgado). Além disso, podemos observar, ao mesmo tempo, a qual temática corresponde cada encaminhamento de projeto e se o projeto - dentre os aprovados - possuem medidas vinculantes. Vale ressaltar que a Resolução para eliminar toda forma de violência contra mulheres, meninas e adolescentes não possui autoria especifica - sendo um documento produzido em conjunto e em nome da Assembleia Nacional -, não sendo incluída, portanto, na seguinte análise. 
Quadro 4- Proposição dos Projetos de Lei por Autoria

\begin{tabular}{|c|c|c|c|c|}
\hline Projetos de Lei & $\begin{array}{l}\text { Mecanismo } \\
\text { Vinculante }\end{array}$ & $\begin{array}{l}\text { Proposto por } \\
\text { Deputada }\end{array}$ & $\begin{array}{l}\text { Proposto por } \\
\text { Deputado }\end{array}$ & $\begin{array}{l}\text { Proposto pelo } \\
\text { Presidente }\end{array}$ \\
\hline $\begin{array}{l}\text { Temática } 1 \\
\text { Lei Orgânica de Comunicação }\end{array}$ & $\mathrm{X}$ & & $\begin{array}{l}\text { Rolando José } \\
\text { Panchana Farra }\end{array}$ & \\
\hline Código Orgânico Integral Penal & $\mathrm{X}$ & & & $\mathrm{X}$ \\
\hline $\begin{array}{l}\text { Projeto de Lei Orgânica contra a } \\
\text { Discriminação, Perseguição e Violência } \\
\text { Política em razão de Gênero }\end{array}$ & & $\begin{array}{l}\text { Lourdes Licenia } \\
\text { Tibán Guala }\end{array}$ & & \\
\hline $\begin{array}{l}\text { Projeto de Lei Orgânica Reformatória à Lei } \\
\text { Contra Violência à Mulher e a Família }\end{array}$ & & $\begin{array}{l}\text { Marisol Peñafiel } \\
\text { Montesdeoca }\end{array}$ & & \\
\hline $\begin{array}{l}\text { Projeto de Lei Orgânica Reformataria à Lei } \\
\text { Orgânica Eleitoral, Código da Democracia } \\
\text { para a Prevenção e Sanção da Perseguição } \\
\text { Política Motivada em Razões de Gênero }\end{array}$ & & $\begin{array}{l}\text { Betty Carrillo } \\
\text { Gellegos }\end{array}$ & & \\
\hline $\begin{array}{l}\text { Projeto de Lei Orgânica de Acesso Integral a } \\
\text { uma Vida Livre de Violência de Gênero }\end{array}$ & & $\begin{array}{l}\text { Marisol Peñafiel } \\
\text { Montesdeoca }\end{array}$ & & \\
\hline $\begin{array}{l}\text { Temática } 2 \\
\text { Lei Orgânica dos Conselhos Nacionais para } \\
\text { a Igualdade }\end{array}$ & $\mathrm{X}$ & & & $\mathrm{X}$ \\
\hline $\begin{array}{l}\text { Código Orgânico de Organização Territorial, } \\
\text { Autonomia e Descentralização }\end{array}$ & $\mathrm{X}$ & & & $\mathrm{X}$ \\
\hline $\begin{array}{l}\text { Projeto de Lei de Igualdade entre Mulheres } \\
\text { e Homens e Pessoas de Diversa Condição } \\
\text { Sexo-genérica }\end{array}$ & & $\begin{array}{l}\text { Paola Verenice } \\
\text { Pabon Caranqui }\end{array}$ & & \\
\hline $\begin{array}{l}\text { Projeto de Lei Orgânica de Igualdade entre } \\
\text { Mulheres e Homens }\end{array}$ & & $\begin{array}{l}\text { Marisol Peñafiel } \\
\text { Montedeoca }\end{array}$ & & \\
\hline $\begin{array}{l}\text { Projeto de Lei Orgânica para a Participação } \\
\text { Equitativa de Mulheres e Homens em Posi- } \\
\text { ções de Liderança no Setor Público e Privado }\end{array}$ & & $\begin{array}{l}\text { Marisol Peñafiel } \\
\text { Montedeoca }\end{array}$ & & \\
\hline $\begin{array}{l}\text { Temática } 3 \\
\text { Lei do Esporte, Educação Física e Recreação }\end{array}$ & $\mathrm{X}$ & & $\begin{array}{l}\text { Celso Pablo } \\
\text { Maldonado } \\
\text { Arboleda }\end{array}$ & \\
\hline $\begin{array}{l}\text { Projeto de Lei da Prática Intercultural para } \\
\text { o Parto Acompanhado no Sistema Nacional } \\
\text { de Saúde }\end{array}$ & & $\begin{array}{l}\text { Lourdes Licenia } \\
\text { Tiban Guala }\end{array}$ & & \\
\hline $\begin{array}{l}\text { Projeto de Lei para Prevenção, Diagnóstico, } \\
\text { Controle e Vigilância do Câncer de Mama }\end{array}$ & & $\begin{array}{l}\text { Silvia Salgado } \\
\text { Andrade }\end{array}$ & & \\
\hline $\begin{array}{l}\text { Temática } 4 \\
\text { Lei Reformatória à Lei de Seguridade Social }\end{array}$ & $\mathrm{X}$ & $\begin{array}{l}\text { Nivea Luz Maria } \\
\text { Velez Palacio; } \\
\text { Cynthia Viteri } \\
\text { Jimenez }\end{array}$ & $\begin{array}{l}\text { Linder Maximiliano } \\
\text { Altafuya Loor; } \\
\text { Rolando José } \\
\text { Panchana Farra } \\
\end{array}$ & \\
\hline $\begin{array}{l}\text { Projeto de Lei que Garante a Seguridade } \\
\text { Social a Mulheres que Realizam Trabalho } \\
\text { Doméstico não Remunerado }\end{array}$ & & $\begin{array}{l}\text { Silvia Salgado } \\
\text { Andrade }\end{array}$ & & \\
\hline $\begin{array}{l}\text { Projeto de Lei de Proteção e Assistência a } \\
\text { Mães Adolescentes }\end{array}$ & & & $\begin{array}{l}\text { Leandro Cadena } \\
\text { Villarreal }\end{array}$ & \\
\hline $\begin{array}{l}\text { Temática } 5 \\
\text { Lei Orgânica de Educação Intercultural }\end{array}$ & & & & $\mathrm{X}$ \\
\hline Total & & 11 & 4 & 4 \\
\hline
\end{tabular}

Fonte: Elaboração própria a partir do banco de dados disponível (ASAMBLEA NACIONAL REPUBLICA DEL ECUADOR, 2018). 
A partir da análise do Quadro 4, a primeira observação é que dentre os 7 projetos que foram aprovados - e dos 6 que possuem medidas vinculantes - apenas 1 possui participação de mulheres em sua proposição, que é o caso da Lei Reformatória à Lei de Seguridade Social, que possui proposição mista. Os outros 6 projetos que foram aprovados - dentre eles 5 com medidas vinculantes - foram propostos pelo Presidente Rafael Correa Delgado ou por deputados.

A segunda observação é que dentre os 12 projetos que são voltados para questões de gênero, que inclui a Lei Orgânica dos Conselhos Nacionais para a Igualdade e todos os projetos arquivados, unificados ou em trâmite, 10 foram propostos por deputadas - sendo que a deputada Lourdes Licenia Tibán Guala propôs 2 projetos, a deputada Marisol Peñafiel Montesdeoca propôs 4 projetos, a deputada Silvia Salgado Andrade propôs 2 projetos, e as deputadas Betty Carrillo Gellegos e Paola Verenice Pabon Caranqui propuseram 1 projeto cada ${ }^{7}$. A Lei Orgânica dos Conselhos Nacionais para a Igualdade foi proposta pelo Presidente Rafael Correa Delgado, e o Projeto de Lei de Proteção e Assistência a Mães Adolescentes foi apresentado pelo deputado Leandro Cadena Villarreal.

A terceira observação é que em relação às temáticas dos projetos de lei, a tendência dos projetos propostos pelas mulheres segue a tendência geral observada de privilegiar as temáticas 1 e 2 (promoção do combate à discriminação e violência contra mulheres; e promoção e transversalização da igualdade de gênero).

\section{Votações dos projetos de lei}

Apresentaremos aqui, a partir do Quadro 5, a relação entre alguns projetos aprovados e o processo de votação na Assembleia Nacional, para depois analisarmos a participação de deputadas na aprovação de projetos que impactaram a promoção da igualdade de gênero no país. Vale ressaltar que grande parte das votações não puderam ser trabalhadas aqui, uma vez que as informações sobre o processo de votação na Assembleia Nacional não estão mais disponíveis - apenas os processos de votação a partir de 2013 estão disponíveis na base de dados da Assembleia Nacional do Equador.
7. A fim de compor o cenário da distribuição de autorias de mulheres dos projetos estudados, vale explicitar a relação das deputadas aqui citados com os partidos políticos. Apesar da categoria partido político não ser o foco da nossa discussão, tal relação deve ser mencionada: as deputadas Betty Carrillo Gellegos, Marisol Peñafiel Montesdeoca, Paola Verenice Pabon Caranqui e Silvia Salgado Andrade pertencem ao partido do governo de Rafael Correa, - Alianza PAIS; as deputadas Lourdes Licenia Tibán Guala e Nivea Luz Maria Velez Palacio pertencem ao partido Alianza de la Izquierda Democrática; e a deputada Cynthia Viteri Jimenez pertence ao partido Partido Social Cristiano (REPÚBLICA DEL ECUADOR, 2016).

Quadro 5- Votações Disponíveis de Projetos Aprovados

\begin{tabular}{l|l|l|l}
\hline Projetos Aprovados & Votos de Aprovação/quórum & Votos Contra & Abstenções \\
\hline Lei Orgânica dos Conselhos Nacionais para a Igualdade & $90 / 116$ & 1 deputado & $\begin{array}{l}18 \text { deputados } \\
7 \text { deputadas }\end{array}$ \\
\hline Lei Orgânica de Comunicação & $108 / 135$ & $\begin{array}{l}19 \text { deputados } \\
7 \text { deputadas }\end{array}$ & 1 deputado \\
\hline Código Orgânico Integral Penal & $101 / 130$ & $\begin{array}{l}21 \text { deputados } \\
8 \text { deputadas }\end{array}$ & 1 deputado \\
\hline
\end{tabular}

Fonte: Elaboração própria a partir dos respectivos documentos de votação (ASAMBLEA

NACIONAL REPUBLICA DEL ECUADOR, 2014); (ASAMBLEA NACIONAL REPUBLICA

DEL ECUADOR, 2013a); (ASAMBLEA NACIONAL REPUBLICA DEL ECUADOR, 2013b).

Apesar do número pequeno de dados adquiridos referentes aos processos de votação de projetos de lei aprovados, os três projetos (Lei Orgânica dos Conselhos Nacionais para a Igualdade, Lei Orgânica de Comunicação 
e Código Orgânico Integral Penal) lidam com importantes questões voltadas para a igualdade de gênero e defesa dos direitos das mulheres. Todos eles foram aprovados com uma maioria significativa dos votos; e em relação aos votos que foram contra, ou aos votos de abstenção, a proporção dos votos de deputados para de deputadas é maior que o dobro.

Na votação da Lei Orgânica dos Conselhos Nacionais para a Igualdade, apenas um deputado votou contra e 25 congressistas se abstiveram, sendo que apenas $28 \%$ destes eram deputadas. Na votação da Lei Orgânica de Comunicação, 26 congressistas votam contra, sendo que apenas $26 \%$ destes eram deputadas, e apenas um deputado se absteve da votação. $\mathrm{E}$ na votação do Código Orgânico Integral Penal, 29 congressistas votaram contra, sendo que apenas $27 \%$ destes eram deputadas, e apenas um deputado se absteve da votação. Sendo que a representação de mulheres na Assembleia Nacional equivale a $43,07 \%$, podemos observar a tendência, nos casos aqui mencionados, de uma maior resistência por parte de deputados em aprovar os referidos projetos. Apesar dos dados não nos permitirem nenhuma afirmação generalista, eles apontam para uma proporção semelhante do comportamento dos votos de deputados e deputadas em relação à aprovação de projetos que impactam significativamente a vida de mulheres equatorianas.

A atuação de deputadas do legislativo equatoriano

Podemos perceber ao longo da subseção 4.1, portanto, que as deputadas que atuaram a partir de 2009 na Assembleia Nacional - marco da institucionalização das políticas de cotas legislativas para mulheres no Equador -, possuem um padrão de interação similar, no cenário legislativo equatoriano, em relação à proposição de políticas voltadas para a promoção da igualdade entre gêneros e direitos das mulheres. Dentre os projetos identificados como voltados para questões de gênero, a grande maioria foi proposta por deputadas $-83,3 \%$ dos projetos estudados -, sendo a maior parte relacionada às temáticas do combate à violência contra mulheres e da promoção da igualdade transversal de gênero - representando $70 \%$ dos projetos propostos por mulheres e voltados para questões de gênero.

Outro ponto importante é que apenas um projeto aprovado - representando $14,2 \%$ dos projetos aprovados estudados - possui participação direta de deputadas em sua proposição. Porém, dos projetos aprovados aos quais tivemos acesso ao processo de votação, percebemos a tendência de uma maior resistência por parte de deputados em aprovar os referidos projetos, ao observarmos a distribuição entre os votos contrários ou de abstenção em relação aos projetos de lei - sendo que a atuação de deputadas não ultrapassou $28 \%$ dos votos que sinalizaram rejeição. Vale ressaltar, porém, que a aprovação de tais projetos é alta, possuindo mais de $74 \%$ dos votos válidos nos três casos apresentados.

Observamos, também, que 5 propostas encaminhadas por deputadas foram arquivadas ou unificadas a outros projetos. Porém, observamos, ainda, que muitas das políticas propostas por essas parlamentares são recentes e ainda estão em processo de qualificação/avaliação/votação 
na Assembleia Nacional - dos 12 projetos estudados que são voltados para questões de gênero, 5 projetos de autoria feminina estão tramitando no parlamento, já que foram propostas entre os anos de 2012 e 2016.

Tais projetos propostos e que ainda estão tramitando na Assembleia Nacional do Equador revelam que para essas deputadas muitas das problemáticas relacionadas às temáticas aqui categorizadas ainda não foram totalmente solucionas, ou incluídas de modo satisfatório, nos projetos de lei previamente aprovados pelo parlamento. Dessa forma, esses novos projetos insistem nas discussões sobre: 1) a necessidade de garantir maior acesso das mulheres a serviços de saúde, de maneira inclusiva e democrática; 2) a importância de implementar mecanismos que garantam a participação equitativa de mulheres e homens em posições de liderança em ambientes públicos e privados no país; 3) a demanda por medidas de proteção, punição e prevenção para combater a perseguição política sofrida por mulheres; 4) a necessidade de ampliar e aprofundar os mecanismos de combate a todos os tipos de violência sofridos por mulheres na sociedade equatoriana.

A partir dessa reflexão, podemos considerar que apesar de importantes projetos, que atendem a demandas relacionadas às temáticas aqui expostas e que possuem medidas vinculantes, terem sido aprovados no Equador nos últimos anos; as deputadas da Assembleia Nacional aqui citadas estão sinalizando para a necessidade de ampliar, aprofundar e incluir demandas e problemáticas relacionadas à igualdade de gênero e direitos das mulheres nas propostas do legislativo nacional. Assim, mesmo que muitas de suas propostas tenham sido incluídas nas discussões parlamentares, e de importantes resoluções e projetos de lei terem ganhado destaque na esfera legislativa, a atuação dessas deputadas da Assembleia Nacional aparece como um elemento importante na reivindicação de uma política mais inclusiva e igualitária, que enfatiza projetos voltados para questões de gênero e dos direitos das mulheres. Dessa forma, entendemos que a participação de mulheres no legislativo nacional do Equador contribui para iniciativas que tem por objetivo a promoção da igualdade de gênero.

A agenda de gênero no Equador

Ao longo do presente trabalho apresentamos uma série de informações a respeito de como políticas voltadas para questões de gênero ou que tocam questões de gênero e de direitos das mulheres foram propostas e aprovadas na Assembleia Nacional equatoriana. Chegamos à consideração, na subseção anterior, que a atuação de deputadas do legislativo nacional do país possui grande importância, não apenas no processo de proposição e aprovação de políticas, mas também na insistência em incluir determinadas pautas na agenda política do Equador, por meio do encaminhamento de projetos de lei recentes. Contudo, para compormos de forma mais aprofundada o cenário político observado ao longo da pesquisa, discutiremos outras variáveis relevantes e resgataremos o argumento teórico do trabalho para discutir sobre a promoção da igualdade de gênero no país. 
8. 1) reprodução e sustentabilidade da vida; 2) uma vida livre de violência; 3) educação e conhecimento; 4) saúde;

5) esporte e recreação; 6) cultura comunicação e arte; 7) produção e emprego; 8) ambiente; 9) poder e tomada de decisões (CONSEJO NACIONAL DE IGUALDAD DE GÉNERO, 2014).
Em primeiro lugar, observamos ao longo da pesquisa a importância que instrumentos e tratados internacionais tiveram no processo de interiorização da temática da igualdade de gênero nos princípios do Estado equatoriano e em muitos dos projetos de lei estudados. A indicação mais clara de tal interferência foi encontrada no documento da Resolução para eliminar toda forma de violência contra mulheres, meninas e adolescentes, que foi promulgada em comemoração ao Dia Internacional da Eliminação da Violência Contra a Mulher, e que destaca elementos de cooperação internacional importantes sobre a temática da promoção da igualdade de gênero. Dessa forma, observamos que a própria Declaração Universal dos Direitos Humanos e o Pacto Internacional de Direitos Civis e Políticos é usado para embasar a defesa pelos direitos das mulheres, pela não discriminação e pela igualdade entre homens e mulheres. Além disso, a Convenção para Eliminação de todas as formas de Descriminação contra a Mulher (CEDAW) aparece como um compromisso vinculante que orienta a criação de medidas que garantam a erradicação da discriminação contra a mulher. E a Convenção Interamericana para Prevenir, Sancionar e Erradicar a Violência contra a Mulher vincula o Estado no sentido de estabelecer medidas para erradicar tal violência (REPÚBLICA DEL ECUADOR, 2014b).

Por fim, mas não menos importante, destacamos a Plataforma de Pequim como responsável por difundir a pauta do empoderamento de mulheres, estabelecendo a recomendação pela criação de mecanismos institucionais para o avanço das mulheres em diferentes esferas, contribuindo para a criação das políticas de cotas no país; e, juntamente com o I Foro Parlamentario Beijing, influenciou a Assembleia Nacional a empreender ações conjuntas com outras instâncias estatais no sentido de fazer esforços para erradicar a violência de gênero contra as mulheres, meninas e adolescentes (REPÚBLICA DEL ECUADOR, 2017). Dessa forma, entendemos que os tratados internacionais, apesar de não terem determinado a implementação de cotas no Equador e a adoção de políticas públicas voltadas para gênero, aparecem como marcos importantes que ajudam a embasar a adoção de tais políticas.

Em segundo lugar, devemos destacar que apesar do presente trabalho ter se limitado ao estudo e análise dos projetos de lei e da incorporação da categoria de gênero no âmbito do Poder Legislativo do Equador, o papel do Poder Executivo não poder ser descartado, sendo uma variável que influencia profundamente a agenda política de gênero no país. Conseguimos observar, ao longo do presente capítulo, que a agência do Presidente Constitucional da República Rafael Correa Delgado foi primordial no encaminhamento de projetos que impactaram profundamente a realidade de mulheres equatorianas. Dos 7 projetos estudados que foram aprovados, 4 foram submetidos pelo presidente, sendo que 3 deles possuem medidas vinculantes.

A Lei Orgânica dos Conselhos Nacionais para a Igualdade prevê a criação de um aparato institucional de proporções extraordinárias, que atinge todos os níveis governamentais do país, e que estabelece a criação do Conselho Nacional para a Igualdade de Gênero. O Conselho estabelece a agenda de gênero em todo o território nacional, incluindo diversos eixos ${ }^{8}$; além de recomendar, acompanhar e monitorar as políticas públicas voltadas 
para gênero criadas no país (REPÚBLICA DEL ECUADOR, 2014c). O Código Orgânico de Organização Territorial, Autonomia e Descentralização, de forma semelhante, possui grandes proporções e procura institucionalizar mecanismos nos âmbitos dos GADs; dentre eles, instituir as Comissões Permanentes de Igualdade e Gênero e os Conselhos Cantonais para a Proteção dos Direitos para agir em sintonia com o Conselho Nacional para a Igualdade de Gênero (REPÚBLICA DEL ECUADOR, 2010a). Já o Código Orgânico Penal Integral especifica diversos crimes e prevê penas e sanções para crimes de feminicídio, discriminação, violência e crimes de ódio, contribuindo para o combate, punição e prevenção de tais crimes (REPÚBLICA DEL ECUADOR, 2014a). Dessa forma, a ação do presidente foi fundamental para institucionalizar aparatos preciosos em defesa dos direitos das mulheres equatorianas nos últimos anos, principalmente em relação às temáticas da promoção e transversalização da igualdade de gênero e da promoção do combate à discriminação e violência contra mulheres.

Em terceiro lugar, devemos resgatar o conceito de transversalização do princípio de igualdade e não discriminação em razão de gênero nas funções do Estado, que aparece na Constituição na determinação de que o Estado é responsável por formular e implementar políticas para alcançar a igualdade entre mulheres e homens, através de mecanismos especializados em conformidade com a lei; além de incorporar o enfoque de gênero em planos e programas (REPÚBLICA DEL ECUADOR, 2008). Esse princípio, portanto, baliza vários dos projetos de lei aqui estudados, sendo de extrema importância para a incorporação de diferentes temáticas relacionadas à igualdade de gênero na agenda política do país; destacamos tal princípio na criação dos Conselhos Nacionais para a Igualdade de gênero, uma vez que se torna claro que a categoria de gênero deve ser levada em consideração em todas as instâncias de decisão política do Equador. Tal movimento, portanto, aponta para a incorporação da perspectiva de gênero no Estado equatoriano.

Em quarto lugar, é importante destacar o caráter interseccional dos projetos de lei aqui estudados, tanto em relação às temáticas abordadas quanto em relação às categorias de opressão endereçadas nos projetos. Nesse sentido, grande parte dos projetos estudados incluem a discussão sobre a transversalização da igualdade de gênero em suas discussões e possuem medidas vinculadas à necessidade de sensibilização e educação da população sobre questões de igualdade de gênero, possuindo, assim, um caráter multidimensional. Além disso, muitos projetos, ao se referirem à necessidade de garantir direitos das mulheres ou estabelecer, por exemplo, medidas de proteção, sanção e prevenção a atos de violência contra mulheres; outras categorias de opressão aparecem em consonância, como a questão da desigualdade de raça, etnia, religião, a descriminação contra a população LGTBI, contra pessoas portadoras de deficiência, entre outras. Outros exemplos de tais interseccionalidades seriam a política de promoção da educação, que possui medidas específicas para mulheres de comunidades indígenas; $\mathrm{e}$ o projeto de lei sobre práticas de parto humanizado ou alternativo, que legitima as práticas advindas de comunidades indígenas. Assim, observamos como as categorias de gênero, raça, etnia, orientação sexual, entre outras, muitas vezes perpassam o conteúdo dos projetos em conjunto. 
Em quinto lugar, voltamos a afirmar que a partir da comparação entre as temáticas dos projetos de leis estudados, observamos que muito se tem alcançado em relação à agenda vinculada à promoção do combate à discriminação e violência contra mulheres e à promoção e transversalização da igualdade de gênero no Equador. Tais temáticas foram atendidas com leis robustas, inclusivas, que possuem mecanismos vinculantes e que atingem diferentes níveis institucionais. Confirmamos, também, ao longo da análise dos projetos estudados, a indicação inicial de que a pauta sobre o combate da violência contra mulheres ganha destaque na pauta política equatoriana, uma vez que encontramos uma resolução e 7 projetos de lei vinculados a tal temática, padrão este que se repete quando olhamos para os projetos propostos pelas deputadas. Tal observação pode ser um indicativo de que este problema ainda persiste de maneira sistemática na sociedade equatoriana.

Por fim, resgatando nosso entendimento sobre o sistema patriarcal, percebemos como positiva a ascensão de mulheres à esfera estatal. O adentramento das mulheres na esfera pública foi percebido: 1) por meio da representação descritiva de mulheres - com as políticas de cotas que garantem uma representação paritária entre homens e mulheres no poder legislativo; 2) juntamente com a representação substantiva de mulheres - pela participação ativa de deputadas nos processos de proposição e aprovação de políticas voltadas para a promoção da igualdade de gênero. Assim, através da representação efetiva de mulheres na Assembleia Nacional do Equador altera-se a realidade da composição entre homens e mulheres na política; ao mesmo tempo em que se aprofunda a construção da agenda de gênero no país.

Nesse sentido, a maior representação descritiva de mulheres - ao ressignificar o espaço político, afirmando que o espaço público deve ser acessível a todas as pessoas -, e a maior representação substantiva de mulheres - com a proposição e aprovação de leis que promovem a igualdade de gênero e direitos das mulheres -, contribuem de maneira essencial para a desconstrução de crenças e práticas excludentes que sustentam a ordem hegemônica masculina. Assim, é possível afirmar que a Assembleia Nacional do Equador, composta no momento da pesquisa de $43 \%$ de mulheres, possuindo mulheres na presidência e nas posições de vice-presidência, possuindo importantes projetos de lei aprovados - e em trâmite-que estabelecem medidas vinculantes sobre temas valiosos à promoção da igualdade de gênero, abriu espaço para a construção de uma realidade mais justa e igualitária entre homens e mulheres na sociedade equatoriana.

Portando, os projetos de lei propostos, que foram estudados, pretendem promover os direitos das mulheres e alcançar a igualdade de gênero - desde a adoção de um combate rígido a atos de violência contra mulheres; passando pela institucionalização da transversalização de gênero; a valorização do trabalho doméstico e a garantia de seguridade social para mulheres; até o estabelecimento do direito à educação e de assistência à saúde inclusiva e ampla. Dessa forma, tais projetos possuem o potencial de transformar materialmente a realidade de mulheres equatorianas, e de alterar os valores e bases ideológicas da sociedade. Assim, a partir da 
alteração da divisão de poder entre homens e mulheres na política, e do aprofundamento da agenda de gênero, o processo de despatriarcalização do Estado ganha materialidade.

É preciso ressaltar, enfim, que diante dessa transformação no espaço político equatoriano, consideramos que a representação descritiva de mulheres influenciou a representação substantiva de mulheres, na medida em $83,3 \%$ dos projetos estudados - todos eles submetidos à Assembleia Nacional após a implementação da política de cotas para mulheres -, e que foram considerados voltados especificamente para questões de gênero, foram propostos por deputadas. Assim, apesar da maioria dos projetos estudados que foram aprovados terem sido propostos pelo poder executivo ou por deputados, consideramos que a atuação de mulheres na Assembleia Nacional constitui um elemento essencial para a aprovação de tais políticas e para a proposição de novos projetos que trazem para o âmbito da política as discussões especificadas acima, contribuindo para a transformação da estrutura e dos valores da sociedade equatoriana, no sentido de alcançar maior igualdade e justiça de gênero.

Nesse sentido, a análise aqui realizada sobre a atuação política de deputadas da Assembleia Nacional da República do Equador sinaliza para a necessidade de ampliar, aprofundar e incluir demandas e problemáticas relacionadas à igualdade de gênero e direitos das mulheres nas propostas do legislativo nacional. Assim, a atuação das deputadas da Assembleia Nacional aparece como um elemento importante de reivindicação de uma política inclusiva e igualitária, agindo por meio de instituições políticas para transformar a realidade de mulheres e de outros grupos considerados minoritários no Equador.

Considerações finais

O presente trabalho realizou um estudo sobre a relação entre a representação de mulheres em processos decisórios da política nacional equatoriana e a incorporação da agenda de gênero no Equador. Para analisar a influência de uma maior representação descritiva de mulheres no âmbito legislativo nacional, realizamos um estudo de caso exploratório sobre os projetos de lei propostos e a atuação das deputadas eleitas, a partir do contexto da implementação de políticas de cotas para mulheres.

Após a exposição dos projetos de leis encontrados que são voltados para questões de gênero ou que tocam questões de igualdade entre gêneros e de direitos das mulheres, realizamos uma análise que teve como foco principal o escopo da incorporação das questões de gênero no país e a atuação das deputadas no processo de elaboração e aprovação dos projetos. Concluímos, primeiramente, que muito se tem alcançado no Equador em relação à agenda vinculada à promoção do combate à discriminação e violência contra mulheres e à promoção e transversalização da igualdade de gênero no Equador; uma vez que grande parte dos projetos aprovados estudados instituíram leis abrangentes e com medidas vinculantes que abordam tais temáticas de maneira aprofundada. Em segundo lugar, constatamos que a representação descritiva de mulheres influenciou a representação substantiva de mulheres, na medida em que $83,3 \%$ dos projetos estu- 
dados - todos eles submetidos à Assembleia Nacional após a implementação da política de cotas para mulheres -, e que foram considerados voltados especificamente para questões de gênero, foram propostos por deputadas.

Vale ressaltar, que mesmo a maioria dos projetos estudados que foram aprovados não terem sido propostos por deputadas, consideramos que a atuação de mulheres na Assembleia Nacional constitui um elemento essencial para a aprovação de tais políticas e para a proposição de novos projetos que trazem para o âmbito legislativo discussões que pretendem alcançar maior igualdade e justiça de gênero. Assim, a atuação das deputadas da Assembleia Nacional aparece como um elemento importante de reivindicação de uma política inclusiva e igualitária, clamando pela transformação da realidade enfrentada por mulheres no Equador. Nesse sentido, a partir da ressignificação dos espaços público e privado, a representação de mulheres na política contribui para o processo de despatriarcalização e de transformação do sistema hegemônico masculino - sistema caracterizado ao longo do trabalho como possuindo caráter internacional -, no sentido da promoção da igualdade entre gêneros.

Por fim, devemos pontuar outros elementos importantes na discussão do trabalho e que não puderam ser desenvolvidas, aqui, de maneira aprofundada. Em primeiro lugar, a sistematização dos dados de países que possuem condições parecidas com o cenário político equatoriano em termos de representação descritiva de mulheres no Estado -, poderiam ajudar a compor o quadro latino-americano em termos de como e em que medida a igualdade de gênero está sendo alcançada na região. Em segundo lugar, e em consonância com o ponto anterior, outras comparações possíveis seriam as estabelecidas entre períodos de pré-institucionalização e pós-institucionalização de políticas de cotas para mulheres no poder legislativo de países latino-americanos. Assim, tais estudos poderiam nos fornecer um melhor entendimento acerca da incorporação da agenda de gênero no Estado. Em terceiro lugar, destacamos, também, a importância de estudos que atentem para a implementação das políticas públicas previstas em projetos de lei aprovados. Nesse sentido, o foco de futuras pesquisas ligadas à temática da promoção da igualdade de gênero poderiam se voltar para como, ou de que modo, as políticas públicas previstas em leis ou em programas dos governos latino-americanos conseguem, de fato, ser implementadas. Assim, as considerações aqui realizadas explicitam alguns limites do presente trabalho; ao mesmo tempo em que apontam para possíveis pesquisas que contribuam para as discussões sobre a representação de mulheres na política e a promoção da igualdade de gênero no contexto latino-americano.

Referências

ANDRADE, Silvia Salgado. Memorandum No. PAN-2010, de 2010. Projeto de Lei que Garante a Seguridade Social a Mulheres que Realizam Trabalho Doméstico não Remunerado. Disponível em: <http://ppless.asambleanacional.gob.ec/alfresco/d/d/workspace/SpacesStore/ 28690012-ff1e-4cc1-87fd-f8267a01f325/Proyecto\%20de\%20Ley\%20que\%20Garantiza\%20la\%20 Seguridad\%20Social\%20a\%20las\%20Mujeres\%20que\%20Realizan\%20Trabajo\%20Dom\%E9stico\%20no\%20Remunerado\%20Tr.\%2034438.pdf>. Acesso em: 27 jan. 2017.

ANDRADE, Silvia Salgado. Proyecto de Ley para Prevención, Diagnóstico, Control y la Vigilancia del Cáncer de Mama, de 2012. Disponível em: <http://ppless.asambleanacional.gob. 
ec/alfresco/d/d/workspace/SpacesStore/56eef118-d45e-43e9-a7b8-66d275454cee/Proyecto\%20 de\%20Ley\%20para\%20Prevenci\%F3n,\%20Diagn\%F3stico,\%20Control\%20y\%20la\%20Vigilancia\%20del\%20C\%E1ncer\%20de\%20Mama\%20\%20Tr.\%2096728.pdf>. Acesso em: 28 jan. 2017.

ARENDT, Hannah. Sobre a Violência. Tradução de André Duarte. 3 ed. Rio de Janeiro: Relume Dumará, 1994.

ASAMBLEA NACIONAL REPUBLICA DEL ECUADOR. Leyes Aprovadas. Disponível em: http://www.asambleanacional.gob.ec/es/leyes-aprobadas. Acesso em: 26 jan. 2018.

ASAMBLEA NACIONAL REPUBLICA DEL ECUADOR. Resumen de Votación: Sesión Nro. 283. Votação do Projeto de Lei Orgânica dos Conselhos Nacionais para a Igualdade, em 2014. Disponível em:

$<$ http://documentacion.asambleanacional.gob.ec/alfresco/webdav/Documentos\%20Web/ Votaciones\%20del\%20Pleno/A\%C3\%B10\%202014/Julio/Sesi\%C3\%B3n\%20283\%20del\%20 Pleno\%20\%2801-07-2014\%29/2-\%20Sesi\%C3\%B3n\%20283\%20del\%20Pleno\%20Allanamiento $\% 20$ a $\% 20$ Objeci $\%$ C3\%B3n\%20Parcial\%20del $\% 20$ Ejecutivo $\% 20$ al $\% 20$ Proyecto $\% 20$ de $\% 20$ Ley\%20Org\%C3\%A1nica\%20de\%20los\%20Consejos\%20Nacionales\%20para\%20la\%20Igualdad.pdf $>$. Acesso em: 05 jan. 2017.

ASAMBLEA NACIONAL REPUBLICA DEL ECUADOR. Resumen de Votación: Sesión Nro. 136. Votação do Projeto de Lei Orgânica de Comunicação, em 2013a. Disponível em:

$<$ http://documentacion.asambleanacional.gob.ec/alfresco/webdav/Documentos\%20Web/ Votaciones\%20del\%20Pleno/A\%C3\%B10\%202013/Junio/Sesi\%C3\%B3n\%20136\%20del\%20 Pleno\%20continuaci\%C3\%B3n\%20\%2814-06-2013\%29/9-\%20Sesi\%C3\%B3n\%20136\%20del\%20 pleno\%20continuaci\%C3\%B3n\%20Disposiciones\%20derogaratoria\%20transitorias\%20finales. pdf $>$. Acesso em: 22 jan. 2017.

ASAMBLEA NACIONAL REPUBLICA DEL ECUADOR. Resumen de Votación: Sesión Nro. 257. Votação do Código Orgânico Integral Penal, em 2013b. Disponível em:

$<$ http://documentacion.asambleanacional.gob.ec/alfresco/webdav/Documentos\%20Web/Votaciones\%20del\%20Pleno/A\%C3\%B10\%202013/Diciembre/Sesi\%C3\%B3n\%20257\%20del\%20 Pleno\%20continuaci\%C3\%B3n\%20\%2817-12-2013\%29/4-\%20Sesi\%C3\%B3n\%20257\%20continuaci\%C3\%B3\%20del\%20Pleno\%20Reformas\%20al\%20C\%C3\%B3digo\%20Org\%C3\%A1nico\%20 de $\% 201 \mathrm{la} \% 20 \mathrm{Ni} \% \mathrm{C} 3 \% \mathrm{~B} 1 \mathrm{ez} \% 20 \mathrm{y} \% 20$ Adolescencia\%2C\%20C\%C3\%B3digo\%20Org\%C3\%A1nico\%20de $\% 201$ a $\% 20$ Funci\%C3\%B3n\%20Judicial\%20y\%20dem\%C3\%A1s\%20Disposiciones $\% 20$ Generales\%2C\%20Modificatorias\%2C\%20Reformatorias.pdf>. Acesso em: 22 jan. 2017.

BROWN, Wendy. Manhood and Politics: A Feminist Reading in Political Theory. 4 ed. New Jersey, Estados Unidos: Rowman \& Littlefield, 1988.

CARANQUI, Verenice Pabon. Proyecto de Ley de Igualdad entre Mujeres y Hombres y Personas Diversa Condición Sexo Genérica, de 2012. Disponível em: $<$ http://ppless.asambleanacional. gob.ec/alfresco/d/d/workspace/SpacesStore/87f3ff35-1047-4231-b427-2376aabc8da3/Proyecto\%20 de\%20Ley\%20de\%20Igualdad\%20entre\%20Mujeres\%20y\%20Hombres\%20y\%20Personas\%20 Diversa\%20Condici\%F3n\%20Sexo\%20Gen\%E9rica-Tr.\%20101584.pdf>. Acesso em: 17 jan.

CONSEJO NACIONAL DE IGUALDAD DE GÉNERO. Agenda Nacional de Las Mujeres y La Igualdad de Género 2014-2017. Quito: El Telégrafo, 2014.

DAHLERUP, Drude. Increasing Women's Political Representation: New Trends in Gender Quotas. In: INTERNATIONAL IDEA. Women in Parliament: Beyond Numbers. Suecia: Edição Revisada, 2005.

ENLOE, Cynthia. Bananas, Beaches, and Bases. 2 ed. Estados Unidos: University of California Press, 2014.

FARAH, Marta Ferreira Santos. Gênero e políticas públicas. Estudos Feministas. Florianópolis: v.12(1), p. 360, jan-abr. 2004.

GALLEGOS, Betty Carrillo. Proyecto de Ley Orgánica Reformataria a la Ley Orgánica Electoral, Código de la Democracia para la Prevención y Sanción del Acoso Político Motivado en Razones de Género, de 2016. Disponível em:

$<$ http://ppless.asambleanacional.gob.ec/alfresco/d/d/workspace/SpacesStore/ef035248-9ba4-4b56-96b9-8ea8bae42c44/Proyecto\%20de\%20Ley\%20Org\%E1nica\%20Reformatoria\%20 a\%201a\%20Ley\%20Org\%E1nica\%20Electoral,\%20C\%F3digo\%20de\%201a\%20Democracia\%20 para $\% 201 \mathrm{a}$

\%20Prevenci\%F3n\%20y\%20Sanci\%F3n\%20del\%20Acoso\%20Pol\%EDtico\%20Motivado\%20 en\%20Razones\%20de\%20G\%E9nero\%20Tr.\%20256692.pdf>. Acesso em: 28 jan. 2017. 
GUALA, Lourdes Licenia Tibán. Memorandum No. PAN-FC-011, de 2011. Projeto de Lei Orgânica contra a Discriminação, Perseguição e Violência Política em razão de Gênero. Disponível em: <http://ppless.asambleanacional.gob.ec/alfresco/d/d/workspace/SpacesStore/ 71189792-0404-40de-a154-a1b5fe9e6b3f/Proyecto\%20de\%20Ley\%20Org\%E1nica\%20contra\%20 el\%20Discrimen,\%20el\%20Acoso\%20y\%20la\%20Violencia\%20Pol\%EDtica\%20en\%20raz\%F3n\%20del\%20G\%E9nero\%20Tr.\%2088918.pdf>. Acesso em: 27 jan. 2017.

GUALA, Lourdes Licenia Tibán. Proyecto de Ley de Práctica Intercultural para el Parto Acompañado en el Sistema Nacional de Salud, de 2016. Disponível em:

$<$ http://ppless.asambleanacional.gob.ec/alfresco/d/d/workspace/SpacesStore/9f1037a5-afef-4578-a1b2-0314e379a3ca/Proyecto\%20de\%20Ley\%20de\%20Pr\%E1ctica\%20Intercultural\%20 para $\% 20$ el\%20Parto $\% 20$ Acompa\%F1ado\%20en $\% 20$ el $\% 20$ Sistema $\% 20$ Nacional $\% 20 \mathrm{de} \% 20$ Salud\%20Tr.\%2015208.pdf>. Acesso em: 28 jan 2017.

HARTSOCK, Nancy C. M. Money, Sex, and Power: Toward a Feminist Historical Materialism. The Northeastern Series in Feminist Theory. 2 ed. Boston: Northeastern University Press, 1985.

INTER-PARLIAMENTARY UNION. Women in National Parliaments: Situation as of December 2008. Disponível em: <http://www.ipu.org/wmn-e/arc/classif311208.htm>. Acesso em: 05 dez. 2016

INTER-PARLIAMENTARY UNION. Women in National Parliaments: Situation as of December 2009. Disponível em: <http://www.ipu.org/wmn-e/arc/classif311209.htm>. Acesso em: 05 dez. 2016

INTER-PARLIAMENTARY UNION. Women in National Parliaments: Situation as of December 2013. Disponível em: <http://www.ipu.org/wmn-e/arc/classif011213.htm>. Acesso em: 05 dez. 2016.

INTER-PARLIAMENTARY UNION. Women in National Parliaments: Situation as of December 2014. Disponível em: <http://www.ipu.org/wmn-e/arc/classif011214.htm>. Acesso em: 05 dez. 2016.

INTER-PARLIAMENTARY UNION. Women in National Parliaments: Situation as of 1st May 2016. Disponível em: <http://www.ipu.org/wmn-e/classif.htm>.Acesso em: 10 jun. 2016.

LOVENDUSKI, Joni. Introduction: state feminism and the political representation of women. In: LOVENDUSKI, Joni (ed.). State Feminism and Political Representation. Cambridge University Press: New York, 2005.

MATOS, Marlise; PARADIS, Clarisse G. Desafios à despatriarcalização do Estado brasileiro. Dossiê o Gênero da Política: Feminismos, Estado e Eleições. Cadernos Pagu, Campinas, vol. 43, p. 57-118, julho-dezembro, 2014

MONTEDEOCA, Juana Marisol Peñafiel. Proyecto de Ley de Igualdad entre Mujeres y Hombres, de 2012a. Disponível em: <http://ppless.asambleanacional.gob.ec/alfresco/d/d/workspace/SpacesStore/ab5651f1-386f-4e8f-b970-989936520d60/Proyecto\%20de\%20Ley\%20Org\%E1nica\%20de\%20Igualdad\%20entre\%20Mujeres\%20y\%20Hombres-Tr\%20106956-Marisol\%20 Pe\%F1afiel.pdf>. Acesso em: 17 jan. 2017.

MONTEDEOCA, Juana Marisol Peñafiel. Proyecto de Ley Orgánica de Acceso Integral a una Vida Libre de Violencia de Género, de 2016a. Disponível em:

$<$ http://ppless.asambleanacional.gob.ec/alfresco/d/d/workspace/SpacesStore/2e60000d-a310-4162-bef7-c12808f81850/Proyecto\%20de\%20Ley\%20Org\%E1nica\%20de\%20Acceso $\% 20$ Integral\%20a\%20una\%20Vida\%20Libre\%20de\%20Violencia\%20de\%20G\%E9nero\%20Tr.\%20 267816.pdf>. Acesso em: 27 jan. 2017.

MONTEDEOCA, Juana Marisol Peñafiel. Proyecto de Ley Orgánica para la Participación Equitativa de Mujeres e Hombres en Posiciones de Liderazgo em El Sector Público y Privado, de 2016b. Disponível em:

$<$ http://ppless.asambleanacional.gob.ec/alfresco/d/d/workspace/SpacesStore/cdc6e559-4eeb-4c5c-bb7b-aa5481208083/Proyecto\%20de\%20Ley\%20Org\%E1nica\%20para\%20la\%20Participaci\%F3n $\% 20$ Equitativa $\% 20 \mathrm{de} \% 20$ Mujeres $\% 20 \mathrm{y} \% 20$ Hombres $\% 20 \mathrm{en} \% 20$ Posiciones $\% 20$ de $\% 20$ Liderazgo\%20en\%20el\%20Sector\%20P\%FAblico\%20y\%20Privado\%20Tr.\%20241322. pdf $>$. Acesso em: 28 jan. 2017.

MONTEDEOCA, Juana Marisol Peñafiel. Proyecto de Ley Orgánica Reformatoria a la Ley Contra la Violencia a la Mujer y la Familia, de 2012b. Disponível em: $<$ http://ppless.asambleanacional.gob.ec/alfresco/d/d/workspace/SpacesStore/edc0f365-d44f-40a6-b35f-de572c8d58b7/ Proyecto\%20de\%20Ley\%20Org\%E1nica\%20Reformatoria\%20a\%20la\%20Ley\%20Contra\%20 
la\%20Violencia\%20a\%20la\%20Mujer\%20y\%20la\%20Familia\%20Tr.\%20120409.pdf >. Acesso em: 27 jan. 2017.

PETERSON, V. Spike; RUNYAN, Anne Sisson. Global Gender Issues in the New Millennium. 4 ed. Estados Unidos: Westview Press, 2014.

PINHEIRO, Rodrigo Paladino. A Súmula Vinculante. Âmbito Jurídico. Disponível em: $<$ http://www.ambito-juridico.com.br/site/index.php?n_link=revista_artigos_leitura\&artigo_id=2375 > . Acesso em: 03 fev. 2017.

QUOTA PROJECT. Equador. Disponível em: < http://www.quotaproject.org/uid/countryview.cfm?id=67>. Acesso em: 10 mai. 2016.

REPÚBLICA DEL ECUADOR. Asamblea Nacional: Código Orgánico Integral Penal, de 2014a. Disponível em: <http://ppless.asambleanacional.gob.ec/alfresco/d/d/workspace/SpacesStore/c5de1907-b2b8-4ee2-83ca-122fb7c57c62/Registro\%20Oficial\%20N\%B0\%20180\%20 C\%F3digo\%20Org\%E1nico\%20Integral\%20Penal.pdf>. Acesso em: 22 jan. 2017.

REPÚBLICA DEL ECUADOR. Asamblea Nacional: Foro Parlamentario Beijing 20 años después se realizará em la asamblea. Disponível em: <http://www.asambleanacional.gob.ec/es/ noticia/foro-parlamentario-beijing-20-anos-despues-se-realizara-en-la >. Acesso em: 01 jan. 2017.

REPÚBLICA DEL ECUADOR. Asamblea Nacional: Ley Orgánica de Comunicacion, de 2013. Disponível em: <http://ppless.asambleanacional.gob.ec/alfresco/d/d/workspace/SpacesStore/5fofa603-afe7-40a3-94f8-b9477961dc9a/Registro\%20Oficial\%20No.\%2022\%20Ley\%20Org\%E1nica\%20de\%20Comunicaci\%F3n.pdf>. Acesso em: 22 jan, 2017.

REPÚBLICA DEL ECUADOR. Asamblea Nacional: Pleno - Asambleístas. Disponível em: $<$ http://www.asambleanacional.gob.ec/es/pleno-asambleistas>. Acesso em: 03 dez. 2016.

REPÚBLICA DEL ECUADOR. Asamblea Nacional: Resolución que exhorta a las funciones del estado y a los gobiernos autónomos descentralizados para que establezcan y apliquen normas y políticas tendientes a eliminar toda forma de violencia contra las mujeres, niñas y adolescentes, de 2014b. Disponível em: <http://www.asambleanacional.gob.ec/sites/default/ files/resolucion_que_exhorta_a_las_funciones_del_estado_y_a_los_gads_para_que_establezcan_y_apliquen_normas_y_politicas_tendientes_a_eliminar_toda_forma_de_violencia_ contra_las_mujeres_ninas_y_adolescentes_25-11-2014.pdf> Acesso em: 28 dez. 2016.

REPÚBLICA DEL ECUADOR. Código Orgánico de Organización Territorial, Autonomía y Descentralización, de 2010a. Disponível em: <http://ppless.asambleanacional.gob.ec/alfresco/d/d/workspace/SpacesStore/eea99806-ed73-4805-9c7d-b0e8c90f0dbc/Registro\%20Oficial\%20N\%B0\%20303\%20C\%F3digo\%20Org\%E1nico\%20de\%20organizaci\%F3n\%20Territorial,\%20Autonom\%EDa\%20y\%20Descentralizaci\%F3n.pdf.>. Acesso em: 24 jan. 2017.

REPÚBLICA DEL ECUADOR. Constitución de la República del Ecuador. Publicada en el Registro Oficial No. 449, 20 de octubre de 2008. Disponível em: <http://www.asambleanacional. gob.ec/sites/default/files/private/asambleanacional/filesasambleanacionalnameuid-20/transparencia-2015/literal-a/a2/Const-Enmienda-2015.pdf>. Acesso em: 01 jan. 2017.

REPÚBLICA DEL ECUADOR. Ley del Deporte, Educación Física y Recreación, de 2010b. Disponível em: <http://ppless.asambleanacional.gob.ec/alfresco/d/d/workspace/SpacesStore/ 3fd2a4c9-57d1-402c-b978-5c5ea071442d/Registro\%20Oficial\%20No.\%20255\%20Ley\%20del\%20 Deporte,\%20Educaci\%F3n\%20F\%EDsica\%20y\%20Recreaci\%F3n.pdf >. Acesso em: 24 jan. 2017.

REPÚBLICA DEL ECUADOR. Ley Orgánica de Educación Intercultural, de 2011. Disponível em: <http://www.evaluacion.gob.ec/wp-content/uploads/downloads/2015/06/Anexo-b.-LOEI.pdf>. Acesso em: 24 jan. 2017.

REPÚBLICA DEL ECUADOR. Ley Reformataria a la Ley de Seguridad Social, de 2010c. Disponível em: <http://ppless.asambleanacional.gob.ec/alfresco/d/d/workspace/SpacesStore/ ff6bcf64-46bc-4f32-8876-562712acd79a/Registro\%20Oficial\%20No.\%20323\%20Ley\%20Reformatoria\%20de $\% 201 \mathrm{a} \% 20$ Ley $\% 20 \mathrm{de} \% 20$ Seguridad\%20Social\%20en $\% 20$ Beneficio $\% 20 \mathrm{de} \% 20$ las\%20Personas\%20que\%20Realizan\%20Trabajo\%20Dom\%E9stico\%20No\%20Remunerado. pdf $>$. Acesso em: 27 jan. 2017.

REPÚBLICA DEL ECUADOR. Registro Oficial: Año II - No 283 Quito, lunes 7 de julio de 2014c. Lei dos Conselhos Nacional para a Igualdade. Disponível em: $<$ http://ppless.asambleanacional.gob.ec/alfresco/d/d/workspace/SpacesStore/2d8c9424-3e3b-45fa-bc2e-8c2600ef7a35/ Registro\%20Oficial\%20No.\%20283\%20Ley\%20Organica\%20Consejos\%20Nacionales\%20 para\%20la\%20Igualdad.pdf >. Acesso em: 05 jan. 2017.

RUBIN, Gayle. The Traffic in Women: Notes on the "Political Economy" of Sex. In: REITER, Rayna R. (ed.). Toward an Anthropology of Women. New York: Monthly Review Press, p.157-210, 1975. 
SCHAVELZON, Salvador. Plurinacionalidad y Vivir Bien/Buen Vivir Dos conceptos leídos desde Bolivia y Ecuador post-constituyentes. Quito, Ecuador: Ediciones Abya-Yala, 2015.

SCHOLZ, Roswitha. Patriarchy and Commodity Society: Gender without the Body. In: PENDAKIS, Andrew; DIAMANTI, Jeff; BROWN, Nicholas; ROBINSON, Josh; SZEMAN, Imre. Contemporary Marxist Theory. New York; London: Bloomsbury Academic, 2014.

SILVA, Fabrício. Até onde vai a "onda rosa”? Analise de Conjuntura OPSA. Rio de

Janeiro, n. 2, p. 1-20, fev, 2010.

SPIVAK, Gayatri. Scattered Speculations on the Question of Value. In: PENDAKIS, Andrew; DIAMANTI, Jeff; BROWN, Nicholas; ROBINSON, Josh; SZEMAN, Imre. Contemporary Marxist Theory. New York; London: Bloomsbury Academic, 2014.

VILlarReAL, Leandro. Proyecto de Ley de Protección y Asistencia a Madres Adolescentes, de 2012. Disponível em: < http://ppless.asambleanacional.gob.ec/alfresco/d/d/workspace/ SpacesStore/a949fb27-3fe4-496e-a6c1-abba7e22776d/Proyecto\%20de\%20Ley\%20de\%20Protecci $\% \mathrm{~F} 3 \mathrm{n} \% 20 \mathrm{y} \% 20$ Asistencia\%20a\%20Madres\%20Adolescentes-Tr.\%20106284.pdf>. Acesso em: 28 de jan. 2017.

WALBY, Sylvia. Theorizing Patriarchy. 2 ed. Oxford: Basil Blackwell, 1991. 